\title{
Using computers in education: A concerns-based approach to professional development for teachers
}

\author{
David H. McKinnon \\ Charles Sturt University-Mitchell \\ Patrick C. J. Nolan \\ Massey University
}

\begin{abstract}
During 1987, 1988 and 1989 a secondary schools curriculum research and development project, called the Freyberg Integrated Studies Project was conducted in New Zealand. The project progressively developed and field tested new types of integrated curricula across Grades 8 to 11 as an alternative to the traditional approach. Within these curricula out of class activities, integrated curriculum materials and computer applications all play a key role.

The paper reports on the computer aspect of the professional development programme. Specific topics include: contextual information regarding computers and staffing; early professional development endeavours; the reasons for and the results of applying the Concerns-Based Adoption Model; factors that inhibit and support innovation adoption, and; implications and conclusions. Involvement in the Project presented the teachers with a complexity of demands. The CBAM provided diagnostic information for the structuring of professional development activities. Interventions were designed to reduce teachers' Self Concerns so that higher order Impact Concerns would emerge enabling teachers to develop and implement practices which would lead to more effective educational uses of computers. Results indicate that Self Concerns have progressively diminished and teachers appear willing to investigate and experiment with computer applications in education. Implications for providers of computer inservice programmes are discussed.
\end{abstract}

School based research and development is relatively uncommon in New Zealand secondary education. This kind of work usually falls between the responsibilities of the universities, teachers' colleges, the government department of education and the schools themselves. The Freyberg 
Integrated Studies Project is one such example of school based curriculum research and development. The Project is an innovative approach to teaching core content of the Common Curriculum of New Zealand secondary schools.

The unique nature of this Project lies in the way that it brings together and applies educational principles that have been shown by past and contemporary educational research to enhance the effectiveness of schools (for examples see Nolan and McKinnon, 1989). The operationalisation of these principles is being achieved in three ways through: (i) the incorporation of out-of-class activities as the basis of in-class studies, (ii) the development of computer applications that support integrated studies and, (iii) the creation of curriculum activities and exercises that integrate out-of-class activities and computers with secondary education objectives. Each of these elements can be viewed as a curriculum entity and as an innovation in its own right. The Project was designed so that each of the three elements would be interdependent and interact in mutually supportive ways.

Involvement in the Project presented the teachers with a complexity of demands. In particular they were expected to not only implement a new curriculum approach but develop ways of teaching additional to, and in some cases quite different from the methods they were accustomed to using. In particular, the teachers are being asked to:

- learn how to use computers and associated software and apply these as an integral part of their practice;

- work collaboratively with other teachers in the design and implementation of the major Project components, e.g., developing integrated units of work based upon experiences and data collected during out of class activities and amenable to treatment by computer applications;

- broaden the conventional range of teaching approaches to include inquiry methods, peer tutoring, mastery learning, small group and individualised instruction and develop compatible classroom management strategies.

The purpose of this paper is to report on the computer aspect of the professional development programme of the project. Specific topics covered include: contextual information regarding computers and staffing; early professional development endeavours; the reasons for and the results of applying the Concerns-Based Adoption Model in the development of strategies; factors that inhibit and support innovation adoption, and; implications and conclusions. 


\section{Context}

The Freyberg Integrated Studies Project might best be described as a 'meta-innovation,' comprising three separate innovations with a possible forth innovation lying in the interaction of the elements each with the other. Clearly, the demands being placed on teachers by such a 'metainnovation' requires that special attention be paid to the professional development programme. In coming to use computers, teachers' behaviour in the classroom would be required to change much more than with the implementation other project components. This was because the computer introduced a new dimension to teaching whereas the out of class activities and subject integration, though new, would call upon accumulated experience and professional knowledge. Anticipated change was in the direction of teachers becoming primarily co-learners, organisers and facilitators of learning, rather than the more traditional roles of instructor and demonstrator.

\section{Computers in the Project}

At the outset Project initiators had a clear conception of how computers should be used in the classroom as a tool for learning, as a medium which invites practical applications, and as a vehicle for the integration of subjects. There was therefore, a view that computers in classrooms would be used in a manner similar to the way in which calculators are now used. They were less clear on the specific strategies to be used in bringing teachers to implement this conception of computer use as a routine part of their everyday educational practice. What became apparent was that teachers and researchers would need to negotiate configurations satisfactory to both.

\section{Equipment}

Early in 1987, 32 IBM JX computers (an updated IBM PC Junior), 10 IBM PC Convertibles and 10 Proprinters, donated to the Project by IBM, were delivered to the school. The JXs were all stand alone machines, running under DOS 2.1. Software adopted for use included the Enable 1.1 integrated package and other assorted educational applications. Additional computers were to be provided as the number of students in the Project increased over the three years in order to maintain a ratio of three students per computer earlier demonstrated in a pilot project to be the minimum ratio necessary for the development of student competency and sustained student access. By the beginning of 1988, 15 IBM PS/2 Model 30 computers equipped with colour monitors and 20 Megabytes of hard disk, two IBM ATs and networking hardware had also been acquired, making a total of 57 computer systems to meet the needs of the project. 


\section{Hardware Configurations}

Over the life of the Project the computer configuration within the classrooms has changed a number of times in response to teacher needs, operational difficulties experienced with hardware and software, and a developing conception of how they might be best used.

In 1987, JX computers were placed in two classrooms in the ratio of one computer per three students. The remaining computers were used by the project teachers and the research staff. The PC Convertibles were used by the grade 11 Environmental Studies students and by teachers.

Three major difficulties with this configuration during 1987 necessitated a revision. These were: persistent disk failure due to the need for frequent changing of the Enable program disks; teacher problems both in managing the large number of disks and perhaps more importantly, in adopting new classroom management strategies necessary to cope with the novel environment; and, lower levels of student competency than might have been reasonably expected given the 1 to 3 ratio.

Initially, in order to reduce the number of program disks, a decision was made to upgrade the JXs to DOS 3.2. Due to supply difficulties, a further three months passed before the new disk operating system arrived. Even then, disk failures continued to be common and mitigation of the other problems was minimal.

In an attempt to resolve all of the problems simultaneously, a decision was made to network $30 \mathrm{JXs}$ to two IBM ATs in a two cluster configuration. The networking was completed in January 1988 ready for the new school year. Meanwhile, the 15 PS / 2 systems were distributed amongst the other three specialist Integrated Studies rooms. The PC Convertibles were available for borrowing by teachers and students.

The network dramatically reduced the amount of downtime previously experienced, the teachers became much happier teaching in the laboratory environment which more nearly resembles a "conventional" classroom and, overall student competency began to rise in response to the sustained one on one access.

However, operation of the JX network created new problems associated with the distribution of components of the integrated software package. While networking provides a workable solution it has created barriers to the effective use of the data management program as an educational tool. Teachers find that the solution to this problem is cumbersome and difficult to implement.

In 1989 the JX laboratory was shifted to a larger room and the PS/2s and Convertibles located in a laboratory next door. This was in response to less 
than optimal use of the PS/2s by teachers in 1988, a large number of students wanting regular access to the computer rooms, and emerging school policy covering supervision, security and school-wide use of computers.

\section{Project Personnel: Teachers and Researchers}

Personnel involved in the Project included both school staff and university researchers.

In 1987, a senior teacher was appointed as coordinator of the Integrated Studies programme and six teachers elected to work in the Project. The number of teachers was increased each year as the Project has expanded. By 1989, 12 teachers were centrally involved with the Project along with a further eight who were associated with integrated studies classes. Two of the original seven teachers have left the project, one to a teaching position elsewhere and the other was counselled to withdraw.

The Project Director, who initiated the Project, was released from university teaching duties to work in the school three quarter time in 1987 and 1988, and half time in 1989. A research officer, seconded from the university on a 0.8 basis for two years, had responsibilities in professional development, technical support and research assistance. A third person was appointed for a minimum of one year from July 1987, to work full time in the areas of: the design, development and implementation of the research programme; the inservice training of teachers, and; curriculum development. With the departure of the latter two staff from the Project in November and July 1988, respectively, two full time replacement staff were appointed to continue the research and development work, refine research instruments, and commence the analysis of research data.

\section{Early Professional Development Endeavours}

From the outset there was a recognition by the research and development team that professional development was a crucial factor for successful implementation of each of the key components of the Project.

In the original Project Proposal a request was made for substantial teacher release time to conduct inservice activities (108 teacher release days in 1987, 144 in 1988 and 180 in 1989). In reality very little time has been allocated by the Department of Education - 30 days for seven teachers in 1987, 20 days for 10 teachers in 1988, and 20 days for 20 teachers in 1989.

The form of early professional development endeavours was therefore dictated by the amount of non-contact time available to the teachers. With the exception of the coordinator, who received an allocation of six pupil free periods per week out of a total of 25 , the remaining teachers had to 
teach between 20 and 23 periods each. Given this situation, professional development took the form of research staff working cooperatively with teachers in the classroom and during out of school hours. The work involved designing instructional programs, team teaching and giving demonstration lessons providing technical support and individualised instruction on request, developing out of class activities and accompanying teachers on the trips away.

Design and development of field trips and integrated sequences of work proved to be the least problematic in the early stages since they drew on curriculum areas in which teachers were confident and experienced. With computers, the reverse was the case. The coordinator of the program was the only teacher who had any prior experience in using computers in the classroom.

Professional development with computers during 1987 and 1988 occurred in the context of a changing computer environment and the consequent need for teachers to learn new procedures in response to changing circumstances. In summary, there were four major changes: 1) the upgrade from DOS 2.1 to DOS 3.2 with associated delays; 2 ) the change from stand alone JX systems to a networked JX laboratory; 3 ) the introduction of the PS/ 2 hard drives; and, 4) the relocation of computers from classrooms to laboratories.

Despite the obstacles, many gains were made. All integrated studies classes were using word processing in most aspects of their work. All classes had applied the database and the spreadsheet to a variety of studies generated as result of issues and topics investigated in their integrated programs. Many students were using such applications such as DRAFIX, a computer aided design program, Dr HALO, a graphics program, BYLINE, a desk top publishing program, and others as a result of their introduction in integrated studies. There was a high level of enthusiasm amongst the students for working with computers.

In contrast, the teachers were diverse in their appreciation of how the computer might be used, diverse in their levels of competency and confidence $\mathrm{m}$ using the various applications and diverse in their attitudes and valuations of the computer itself as an educational tool. It was recognised that if a higher minimum level of teacher competence and confidence was to be achieved then a different approach to professional development was required. The Concerns Based Adoption Model developed by researchers at the University of Texas at Austin (Hall, George and Rutherford, 1973) was selected for two reasons. First, it provided a conceptual framework for examining the process of innovation adoption, and second, it provided an empirically validated process for the collection of research data and for the design and delivery of professional development programmes. 


\section{The Concerns-based adoption model (CBAM)}

Development of the CBAM (Hall, Wallace \& Dosset, 1973) was based on extensive experience with educational innovation in school and college settings in the USA. The model has many important implications for the introduction and management of innovation and change in educational settings. The following assumptions establish the model's perspective on innovation adoption.

1. In educational institutions change is a process, not a singular event.

2. The individual must be regarded as the most important target of any interventions which are designed to facilitate change in the classroom.

3. Change is a highly personal and potentially threatening experience.

4. The change process is not a continuous one.

5. Staff development can be best facilitated by the use of a client centred diagnostic/prescriptive approach.

6. Staff developers need to work in an adaptive yet systematic way, staying in touch with the progress of individuals within the organisation. (Hall \& Loucks, 1978, pp 3-5)

The Model is comprised of the basic concepts of Stages of Concern, Levels of Use and Innovation Configuration. The Stages of Concern about an innovation is the developmental hierarchy of concerns in seven stages which individuals typically experience over time as they come to use the elements of the innovation. The seven stages range from Awareness about the innovation and the self concerns of Informational and Personal, through the task concern of Management, to the impact concerns of Consequence, Collaboration and, Refocussing. The Levels of Use of the innovation is an eight level developmental hierarchy of behaviours which describes the type of behaviours individuals exhibit over time in relation to the innovation. The eight levels range from non-use, orientation towards and preparation to use the innovation, through mechanical and routine uses, to refinement, integration and renewal where the user evaluates the quality of use of the innovation and examines new developments in the field with a view to setting new goals. The Innovation Configuration is the operational pattern of the innovation that results from user selection and use of different innovation components. It provides a description of the various adaptations the innovation has made within the user system.

\section{The CBAM Instruments}

Each of the major dimensions of the CBAM, Concerns, Use and Innovation Configuration has an associated instrument which will provide diagnostic information to the staff developer. 
Teachers' concerns may be elicited in a variety of ways: through conversation; through a written responses to open questions, and; through responses to the Stages of Concern Questionnaire (Hall, George \& Rutherford, 1979). The questionnaire produces the most rigorous data of the three. Responses to the questions allow a "Concern's Profile" to be constructed which displays the relative intensity of each of the seven concerns. Interpretation of the profiles is fully described in Hall et al., 1979.

The level at which the teacher is using the innovation is elicited using a focussed interview technique. Teacher responses to questions related to their knowledge about the innovation, planning, sharing, assessing, performing and acquiring information allow an assessment of the teacher's Level of Use of the innovation. The Levels of Use dimension and interview technique and interpretation are described in Loucks, Newlove and Hall, 1975.

The pattern of implementation of the innovation is derived from an Innovation Configuration Checklist. The checklist is constructed in a five step process where the components of the innovation are identified, put together to form an innovation description, and variations for each component are identified from ideal to unacceptable. The checklist thus constructed is then piloted and reviewed before being administered (Heck et al 1981).

All of the above instruments are being used to collect data related to the project.

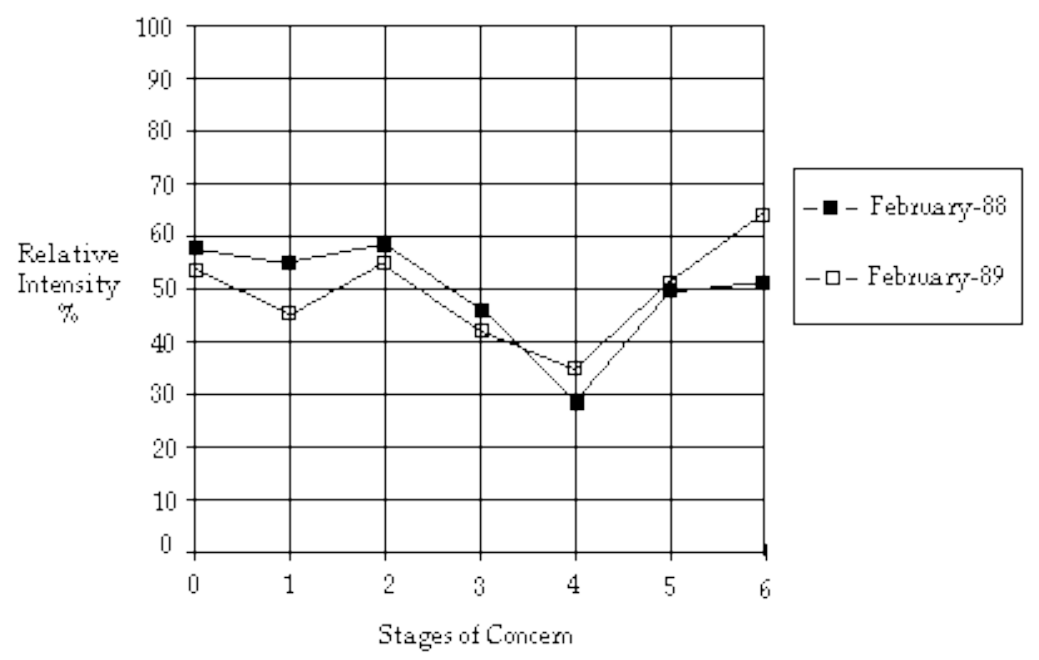

Figure 1: Group Concerns February 1988 and February 1989. 


\section{CBAM Results, Interpretations and Interventions}

The Stages of Concern Questionnaire (SoCQ) was first administered to project teachers in February 1988. Concerns profiles were generated for each of the teachers. The average concerns profile shown in Figure 1 below, indicates that teachers at this time had relatively high personal concerns. Moreover, the Stage 2 -Personal Concerns were higher than the Stage 1 - Information seeking concerns. In many respects, this is an undesirable situation because it signifies that the teachers were more concerned with feelings about their personal adequacy than they were with finding out more about the use of computers in integrated studies.

Early in February 1989 a second SoCQ was administered. The data revealed that there had been little or no change in the concerns profiles of the teachers. Both the February 1988 and 1989 profiles are shown in Figure 1 above.

Although an averaged profile of this nature tells relatively little about individual concerns, it indicates the relatively high Personal Concerns being expressed by the group as a whole. It also serves to illustrate that the Self Concerns have precluded the development of genuine Impact Level concerns. This is indicated by the tailing up at stages 5 and 6 and by the low level of concern being expressed at the Consequence (Stage 4) level. In this case, the users had concerns about what others were doing and, more importantly, ideas about how to do things better. These ideas, when evident in the new user, are usually detrimental to innovation adoption. This is because such ideas commonly involve opposition to the innovation.

This outcome is not altogether surprising given the difficulties that had been encountered with disk failures, the introduction of new computers and a network at the start of 1988 and, the paucity of inservice time.

An analysis of changes to the hardware configuration combined with data from the February 1989 SoC profiles suggested a number of specific interventions to reduce teachers' Personal Concerns. These were: making sure that the teachers were absolutely successful with any new tasks in which they engaged; making sure that the technology actually worked; designing simple instructional sequences on how to use the computer to perform a particular task using annotated screen dumps, e.g., graphing; and, paying more attention to the teachers' concerns than to the technology.

Early in 1989, professional development began with the implementation of a consultative systematic approach. The senior project researcher developed a combination of stand alone and integrated packages in consultation with teachers. There were ten packages in all involving 
aspects of Physics, Chemistry, Environmental Science, Biology, Mathematics, Geography, English and Genetics and the application of data base, spreadsheet, graphing and word processing programs. The teachers made time to familiarise themselves with the packages and the various computer applications. A researcher was present in the classroom when the teacher took the class, "just in case". Teacher participation in the design process varied from intense involvement to simply trying out the computer component and suggesting changes to the sequence. An important outcome was that teachers' expressed a commitment to working with computers and commented on the potential for their respective subject areas.

A further SoCQ was administered close to the end of Term 1. The resultant profiles revealed that some change in the type and level of the teachers' concerns had occurred. Although not significant in the statistical sense, these changes provided some evidence that the intervention strategies were beginning to work. Figure 2 below displays comparative data on the pattern of average teacher concerns encompassing the three surveys.

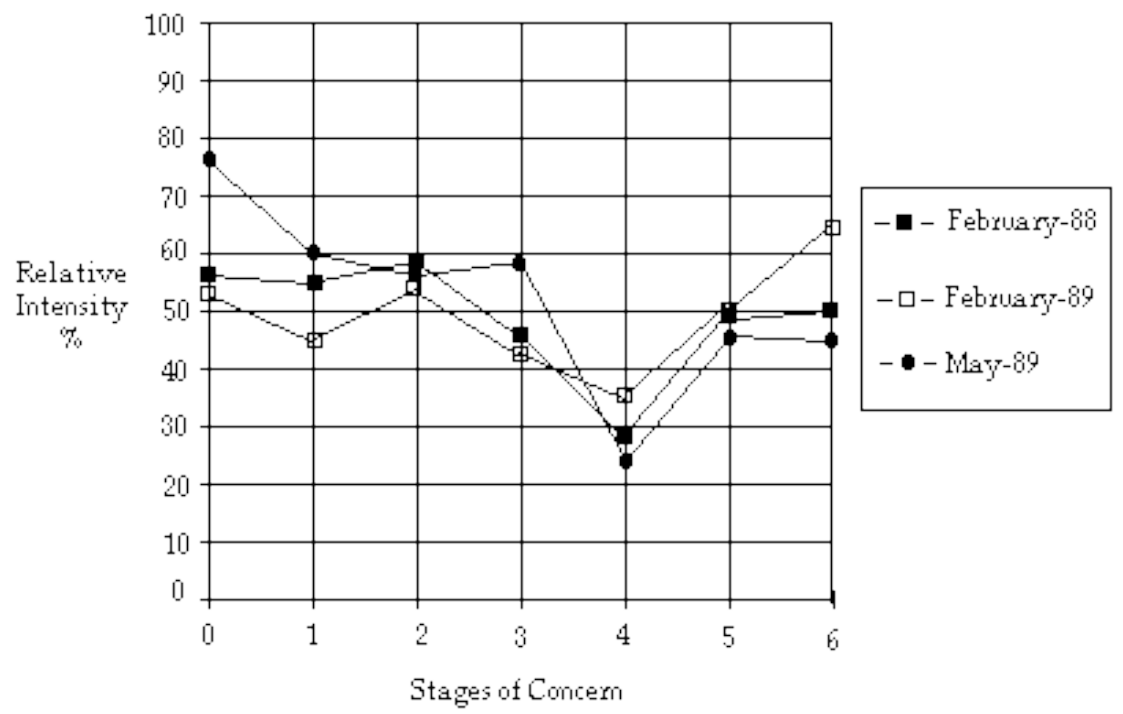

Figure 2: Group concerns for May 1989 contrasted with previous group concerns.

Figure 2 reveals a number of differences between the May 1989 profile and the previous two. The first difference is that there is a difference! Secondly and more importantly, Personal Concerns have fallen and Information seeking concerns (Stage 1) are now higher. A reduction in the former has removed a barrier preventing teachers from seeking further information 
about using computers in the classroom. The small increase in Management Concerns (Stage 3) suggests that the teachers are beginning to think about the need for more time to deal with computer related developments.

The reduction in the Stage 6 - Refocussing concerns is also a positive development. This indicated that teachers' potentially negative ideas about how to do things better had been replaced with a desire to investigate computer education possibilities.

Thus far, average profiles have been used to provide summary data to illustrate group changes. Individual profiles show more marked changes than averaged profiles. The following profile (Figure 3) illustrates the change in concerns of a teaching head of department. The February 1989 survey revealed high Personal Concerns combined with potentially negative ideas about using computers (high Stage 6). By May 1989 Personal Concerns had fallen and been replaced by higher Information and Management Concerns. The peak at the Collaboration level indicates a concern for finding out what other teachers are doing with computers. The latter two peaks are not surprising given the role of this teacher.

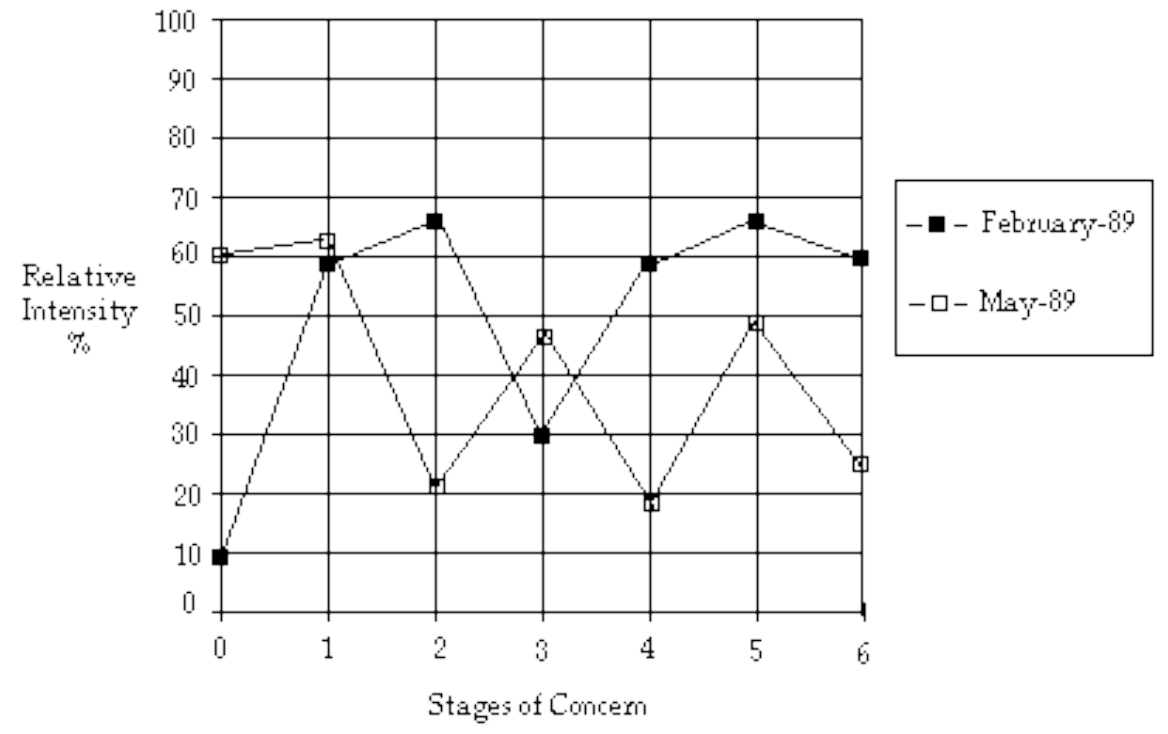

Figure 3: An individual teacher's profile showing change.

A detailed analysis of the individual profiles revealed that the majority of teachers were expressing higher concerns at the Stage 1 and 3 levels. The interventions suggested from these data were: provision of suitable short 
courses so that teachers' questions might be answered; release from face to face teaching so that teachers might more profitably work on aspects of the Project involving computers, and; strategies for time management be addressed.

Levels of Use data collected late in Term 1 of 1989, revealed the depth and extent to which computers were being used by teachers centrally involved in the project. These data are summarised in Table 1 below.

Table 1: Levels of Use of computers, May 1989 (N=12)

\begin{tabular}{|l|c|}
\hline \multicolumn{1}{|c|}{ Level of Use } & Number of Teachers \\
\hline 0 Non use & 0 \\
I Orientation & 1 \\
II Preparation & 2 \\
III Mechanical Use & 4 \\
\hline IVA Routine Use & 3 \\
IVB Refinement & 1 \\
V Integration & 1 \\
VI Renewal & 0 \\
\hline
\end{tabular}

These data indicate that the majority of teachers (7) were using computers at Levels which would be unable to be sustained in the event of no further professional development (McKinnon \& Sinclair, 1988), i.e., the teachers who were at Level III, or lower, would not develop a Routine level of using computers in their classrooms. It has been further suggested that unless $75 \%$ of individuals involved in adopting an innovation are operating at Level IVA or higher, then the innovation will not be able to be sustained if professional development support is removed.

The primary aim of the professional development programme for the second term therefore, was to bring a larger proportion of the teachers to at least the Routine Level of Use which would more likely ensure the continued and developing use of computers. At the same time, any interventions would have to be designed to meet the individual concerns of the teachers. For example, by using the teacher release days (TRDs), teachers' Stage 3 Concerns would be accommodated and, simultaneously, time could be devoted to meeting some other expressed need such as information provision, or how to improve student outcomes using computers in, say, Mathematics.

Short professional development courses of two to three hours duration were conducted, using six of the 20 TRDs allocated by the Department of Education, for the teachers of Integrated Studies, Mathematics, and Science. Subject teachers were grouped using both Concerns data and expressed interest in a particular topic. For example, in Integrated Studies 
the common topic was the construction and use of a database to analyse the change in a community from 1870 to the present day. The level at which this topic was treated varied from Stage 1 - how to go about building the database, and how the database could be used in class, to Stages 4 and 5 -sharing information on how to structure activities so that students would understand that a variety of factors were important in the development of communities. Various topics were covered in Mathematics. These ranged from how to use a graphing program (Stage 1) through to two teachers preparing a third form programme for 1990 using an integrated approach (Stages 4 and 5). In Science, minicourses were primarily aimed at the provision of information on a number of approaches using integrated software, interface equipment, and simulation packages.

A third SoCQ was administered in the final week of Term 2. Teachers who had participated in the professional development courses were surveyed. Data from teachers whose profiles had contributed to the May 1989 averaged profile were used to construct the averaged profile for August 1989. Both profiles are shown below in Figure 4.

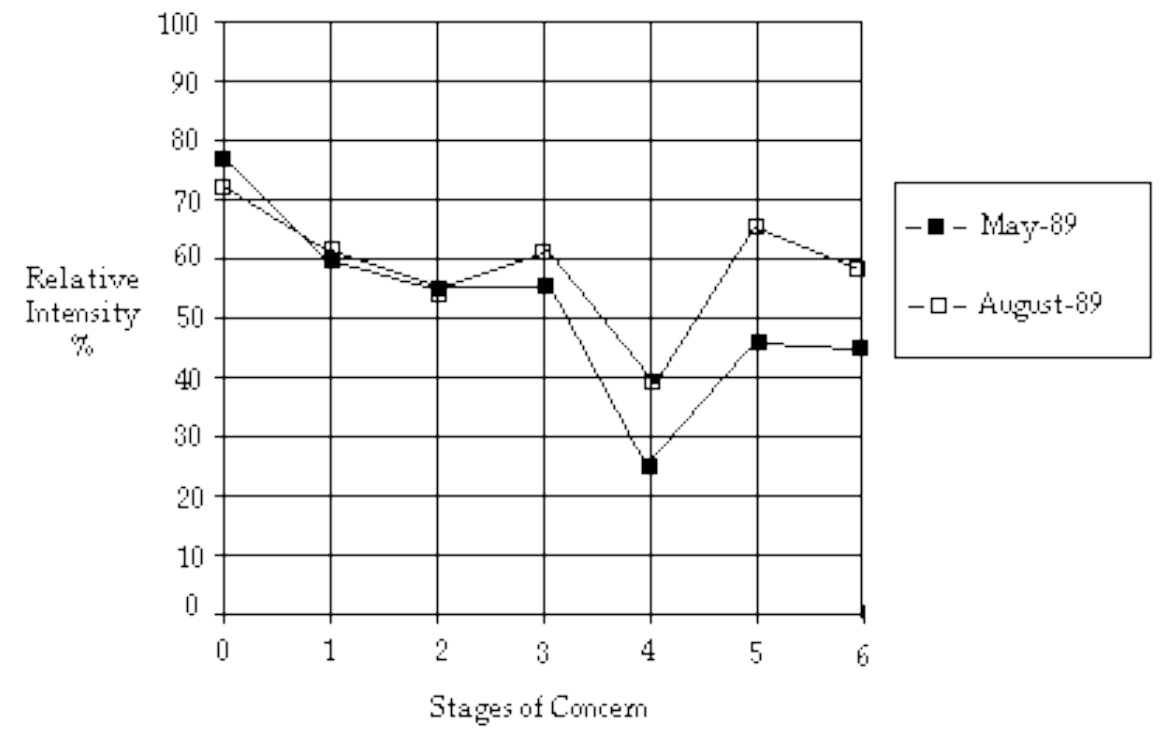

Figure 4: Group concerns for May and August

It was encouraging to note that there was no deterioration in the August profile. Indeed, there were some encouraging trends. The Stage 6 Concerns continued to decrease in relation to the Stage 5 Concerns indicating that the overall negative attitudes towards the use of computers 
in education were diminishing. These concerns were now less intense than the Stage 5 Collaboration Concerns. A second important trend is apparent from the fact that the Stage 2 Personal Concerns continued to be less intense than the Stage 1 Information Concerns. An analysis of the individual profiles revealed that no teachers had their most intense concerns at Stage 2. The third trend was the continuing increase in the Stage 3 Management Concerns. These were now the most intense concerns for 7 of the 12 teachers. To date, their have been no inservice minicourses directed at time management. With the majority of teachers expressing concern at the Stage 3 level such a course needs to be organised and run in the near future.

Levels of Use data collected late in Term 2 revealed the extent to which the teachers' patterns of use had changed. These data are summarised in Table 2 below.

Table 2: Levels of Use of computers, August $1989(\mathrm{~N}=12)$

\begin{tabular}{|l|c|}
\hline \multicolumn{1}{|c|}{ Level of Use } & Number of Teachers \\
\hline 0 Non use & 0 \\
I Orientation & 0 \\
II Preparation & 2 \\
III Mechanical Use & 3 \\
\hline IVA Routine Use & 5 \\
IVB Refinement & 1 \\
V Integration & 1 \\
VI Renewal & 0 \\
\hline
\end{tabular}

Analysis of these data indicated that three teachers had changed their pattern of use. One had moved from Orientation to Preparation while two had moved from Preparation to Routine Use. The teacher whose Level of Use had moved from Orientation to Preparation also showed a dramatic change in the Stages of Concern profile. The Personal Concerns expressed by this teacher dropped from being the most intense to the second least intense and this was accompanied by a rise in the Management Concern indicating that a decision had been made about getting involved but that this was accompanied by a concurrent concern about the amount of time that it would take to become familiar with using the computer in the classroom. The majority of teachers (7) were operating at a Level of Use which could be regarded as self sustaining. There were however, insufficient numbers of teachers operating at this level to allow the maintenance and development of the innovation within the school. A continuing goal of the program was to bring at least $75 \%$ of teachers to at least the Routine Level of Use. 
During the third term, a number of TRDs were used to release teachers for short periods of time to further explore computer applications in Integrated Studies, and to allow planning time for the 1990 academic year. No minicourses were run on time management techniques for teachers. This was primarily due to the gradual withdrawal of the research team in order to allow an increasing sense of ownership to develop. The computer systems were formally handed over to the school by Massey University at a formal ceremony early in November 1989. The final teacher questionnaires were administered shortly thereafter covering Concerns, the Innovation Configuration, Organisational Climate and interviews conducted to ascertain Levels of Use. The Concerns and Levels of Use data are summarised below.

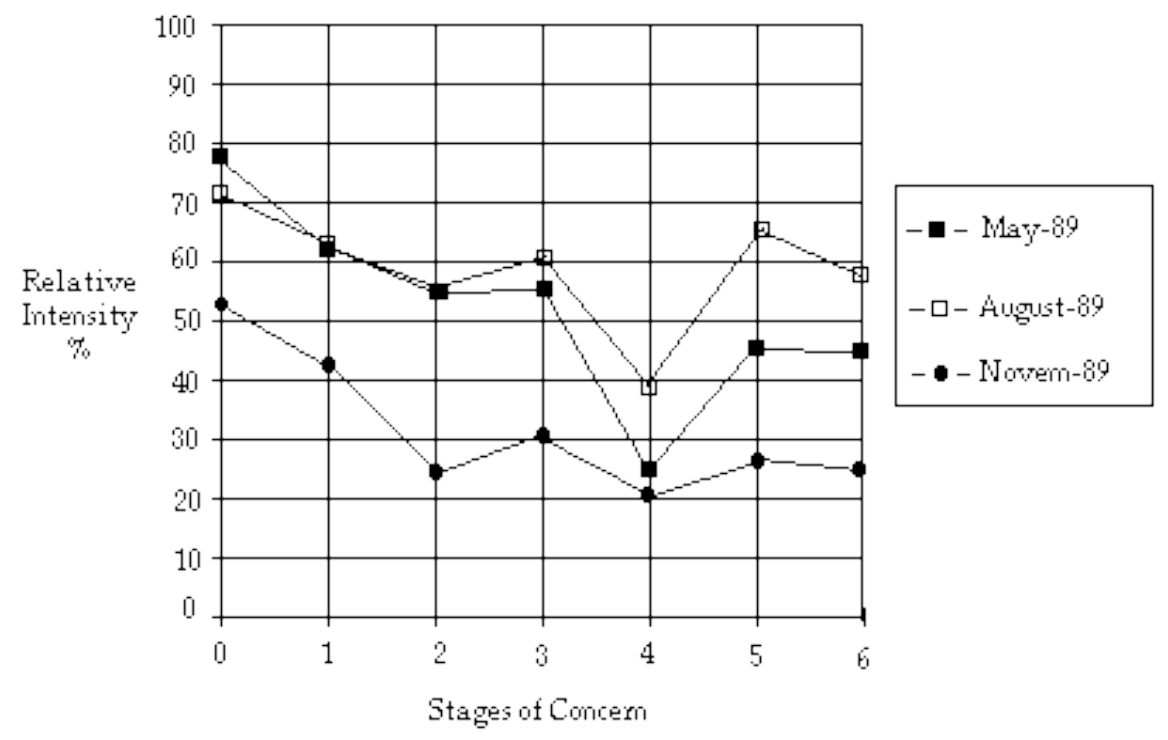

Figure 5: Group concerns for May, August and November 1989.

Figure 5 shows the Integrated Studies teachers' averaged concerns profile for May, August and November. It is noticeable that in the November profile the expressed level of concern at all stages has reduced. Whether this is related to the professional development programme or the proximity of the end of the year is problematic.

It was encouraging to note however, that the intensity of the Stage 2 Personal Concern had diminished markedly in relation to the Stage 1 Information Concern. This reduction is probably more indicative of the effects that the professional development programme has had on the teachers rather than the overall reduction in expressed levels of concern. 
A second observation is that the Stage 3 Management Concerns continue to be relatively high emphasising the need for some form of time management workshop for the teachers. This will, in all probability, continue to be a major concern for the teachers since they are expected to teach rather than spend time in professional development activities.

Levels of Use data collected late in Term 3 revealed the extent to which the teachers' pasterns of use had changed. These data are summarised in Table 3 below.

Table 3: Levels of Use of computers, November 1989 (N=12).

\begin{tabular}{|l|c|}
\hline \multicolumn{1}{|c|}{ Level of Use } & Number of Teachers \\
\hline 0 Non use & 0 \\
I Orientation & 0 \\
II Preparation & 1 \\
III Mechanical Use & 1 \\
\hline IVA Routine Use & 7 \\
IVB Refinement & 2 \\
V Integration & 1 \\
VI Renewal & 0 \\
\hline
\end{tabular}

Analysis of these data indicated that five teachers had changed their pattern of use. One had moved from Preparation to Mechanical Use, Three had moved from Mechanical to Routine Use, and one had moved from Routine to Refinement. The teacher, who had indicated at the end of the second term that they were going to take a computer home during the vacation, had still not actually begun using a computer either for personal purposes or in the classroom when these data were collected. This may indicate that additional factors have to be taken into account when professional development programmes are structured for school staff. It is probable that this teacher experiences anxiety, a different construct to that of a concern, when confronted with the technology.

An Innovation Configuration Description for the whole project has been constructed from the original Project Proposal, documents related to the initial developments and, discussions with the Director of the Project. An Innovation Configuration Checklist, comprising 47 items, has been constructed and is to be administered in the near future. Information about the patterns of adoption will be available to plan overall strategy for the professional development programme, and results reported at a later date. 


\section{Discussion}

Professional development is a key factor in the process of successful innovation adoption. Within the Concerns-Based Adoption Model this process is dialectical in character involving constituent processes of feeling, action and choice. Initially individuals feel a sense of concern related to a specific aspect. Once identified the concern must be addressed in terms of specific actions aimed at resolution of the concern. Resolution in its turn involves conscious choices about further involvement which in its turn gives rise to new and different concerns.

Experiences in the project exemplified the dialectic in action. In some instances teacher adoption of computers was relatively unproblematic. In these cases, the teachers came into the project with a commitment to master the computer and to apply it in the classroom. For example, one teacher took a computer home during the long Christmas vacation and returned in the new school year fired with enthusiasm to apply his new found skills. In contrast, other teachers showed little enthusiasm for the project and were reluctant to spend time in learning how to use computers. With these teachers, there was a mismatch between their concerns and those of the initiators and consequently professional development activities failed to meet their needs. Eager to make progress but lacking insight into the dialectical nature of the problem, the initiators constructed early professional development activities to meet their own concerns rather than those of the teachers.

A further example illustrates both the initial mismatch and the dialectic in action as the dissonance was resolved. At the inception small numbers of computers were placed in the integrated studies classrooms. Researchers were concerned, however, that students were not developing levels of competency and skill commensurate with their ability and the enthusiasm they displayed for working with computers. Moreover, progress in this environment was unlikely to occur unless associated problems of disk failure, student access and teacher management were also addressed and resolved. The researchers deemed it necessary to move the computers into a laboratory. In the laboratory, teachers were secure in the knowledge that they could resort to tried and true whole class instruction and discipline methods. The physical set up of computers in the laboratory permitted the teacher, standing at the front of the class, to maintain surveillance over the whole class.

While this environment appears to encourage progress on a common front, students inevitably progress at different rates. As the teacher responds to an individual's needs others must either wait or seek help elsewhere. Typically, peer tutoring begins to occur and the teacher has little choice but to accept this as a workable basis for conduct of the class. 
This pattern becomes established and management methods are adapted. In response teachers cannot but change or adapt their methods and strategies to meet the demands of the new situation.

Just as the implementation of the Project was daunting for the teachers, the researchers were also faced with the equally daunting task of learning new roles working with and along side teachers in the process of innovation adoption. Moreover, being the initiators of the Project, they had to learn to downplay their concerns for the Project in order to develop and maintain teacher commitment to an enthusiasm for the Project goals and approaches.

Decisions were made in 1989 to offer the Integrated Studies course to all students entering the high school in 1990. Changes are being made to the Innovation Configuration for the sake of administrative expediency. In 1990, for example, Integrated Studies will not be taught by just one teacher. The barriers between subjects in the secondary curriculum are being re-erected. The implications related to bringing all grade 8 teachers into the programme are significant given that the school will be attempting further major change equipped with reduced resources in this time of major change to the structure of education in New Zealand.

The CBAM, however, provides a useful framework within which to analyse the ongoing dialectic of change. The CBAM instruments provide important diagnostic information for staff developers. This permits the selection of appropriate intervention strategies and tactics to facilitate innovation adoption and use while minimising the trauma of change.

\section{References}

Hall, G. E., Archie, G. A. \& Rutherford, W. L. (1979). Measuring Stages of Concern About Innovation: A Manual for the use of the SoC Questionnaire. The University of Texas, Austin, Texas.

Hall, G. E., Wallace, R. C. \& Dosset, W. A. (1973). A Developmental Conceptualization of the Adoption Process with Educational Institutions. The University of Texas, Austin, Texas.

Hall, G. E. \& Loucks S. F. (1978). Teacher Concerns as a Basis for Facilitating and Personalizing Staff Development. Teachers College Record, 80, 1 .

Heck, S., Stiegelbauer, S. M., Hall, G. E. \& Loucks, S. F. (1981). Measuring Innovation Configurations: Procedures and Applications. The University of Texas, Austin, Texas.

Loucks, S. F., Newlove, B. W. and Hall, G. E. (1975). Measuring Levels of Use of the Innovation: A Manual for Trainers, Interviewers and Raters. The University of Texas, Austin, Texas. 
McKinnon, D. H. \& Sinclair K. (1988). Teachers Teaching Teachers: A Concerns Based Approach to Computer Inservice Education. Australian Educational Research, June.

Nolan C. J. P. and McKinnon D. H. (1989). The Freyberg Integrated Studies Project: Rationale, Research and Results. Paper presentation for the NZARE conference, Wellington, New Zealand. A copy of this paper may be obtained by writing to D. H. McKinnon at: School of Teacher Education, Charles Sturt University - Mitchell, BATHURST 2795, Australia.

Authors: David McKinnon can be contacted at Charles Sturt UniversityMitchell, Panorama Avenue, Bathurst NSW.

Please cite as: McKinnon, D. H. and Nolan, P. C. J. (1989). Using computers in education: A concerns-based approach to professional development for teachers. Australian Journal of Educational Technology, 5(2), 113-131.

http: / / www.ascilite.org.au/ajet/ajet5/mckinnon.html 